\title{
The Perfection of the Evaluation System of the State Programs Efficiency as a Strategic Condition of a Social-economic Development Rising
}

\author{
Irina Yurzinova \\ Financial University under the Government of the Russian Federation \\ Moscow, Russia \\ E-mail: IYurzinova@fa.ru
}

\author{
Dmitry Morkovkin \\ Financial University under the Government of the Russian \\ Federation \\ Moscow, Russia \\ E-mail: MorkovkinDE@mail.ru
}

\author{
Aleksey Stepanov \\ Financial University under the Government of the Russian \\ Federation \\ Moscow, Russia \\ E-mail: avstepanov@fa.ru
}

\author{
Olesya Dontsova \\ Financial University under the Government of the Russian \\ Federation \\ Moscow, Russia \\ E-mail: oidontsova@fa.ru \\ Natalia Isaichykova \\ Gomel State Technical University named after P.O. Sukhoi \\ Gomel, Republic of Belarus \\ E-mail: natalyii@mail.ru
}

\begin{abstract}
Improving the mechanism for developing, implementing and evaluating the effectiveness of state programs will help to reduce socio-economic problems in the Russian Federation. The article examines three areas for improving the quality of implementation development and evaluating the effectiveness of state programs: improving the organizational mechanism for their development and implementation, improving the quality of the formation of target indicators of state programs and the universalization of the methodology for calculating the degree of their achievement, the development of the regulatory framework.
\end{abstract}

Keywords-economy; strategic planning; state program; program-target approach; methods of evaluating the effectiveness of state programs; social-economic development

\section{INTRODUCTION}

The federal law dated 28.06.2014 No. 172-FL "The Federal Law On strategic planning in the Russian Federation" creates a complex system of the state strategic planning in Russia, connects the strategic planning with the budget policy, fastens the document composition of the strategic planning and determines the place of state programs in the strategic planning space [1].

The evaluation of social-economic efficiency of state programs allows to fix an overspending or budget resources saving, to compare actual results of the program with targets (indicators). A perfection of the development mechanism, realization or efficiency evaluation of state programs will contribute to social-economic problems reduction in the Russian Federation [2].

In the base of the development quality rising, realization and the efficiency evaluation of state programs is the perfection of the organizing mechanism of its development and realization, the quality improvement of target indexes forming of state programs and universalization of the calculating method for its achievement, the normative legal base development.

\section{The PERFECTION OF THE ORGANIZING MECHANISM DEVELOPMENT AND STATE PROGRAMS REALIZATION}

Inside the budget planning frames functional-department approach still dominates. State programs are not full introduced to budget process because the spending primacy saves comparing to the targets, goals and expected results of the state programs. The efficiency evaluation of a state program is not the main factor of the budget appropriation forming for state programs realization. The federal budget project should be based on the state programs at first, which will connect changes bringing to the federal budget with the goals, problems and expected results of the state programs realization [3].

Nowadays the unregulated problem is the question of the well-timed forming of the state programs realization 
movement reporting: there are no data about the actual meanings of some indexes.

It is necessary to rise the quality of preparation the information about control events realization, the information about actual execution of the federal budget spending, the reasons of deviations from planned parameters of state programs of actual indexes meanings. The control events emphasizing of the state program in the forming process of the mean events selection gives an opportunity to evaluate the subtotals and the last results of the main events achievement during the certain period.

Besides, it is being needed the constant control of the given information reliability according to the fixed procedures, to exclude an opportunity of data manipulation by a responsible performer.

Connecting to the economic instability it is necessary to actualize the realization plans of state programs, taking into account the decisions about the federal budget of the coming period. Such an approach prevents the appearance of essential deviations from the realization movement of the state program from the planned level and allows in the most efficient way to redistribute available resources. Following realizing this step will be considered the results of the efficiency evaluation of the state programs in realizing its adjustment and forming federal budget project.

Based on recommendations by The Ministry of Economic Development in the Russian Federation it can be improved the efficiency evaluation and result efficiency of the budget resources using by the program part of the budget on account of introduction by the Russian Government to the Russian Federation State Duma along with the federal budget project for the regular financial year and planning period of the state programs projects. This way will allow to connect the efficiency evaluation with the results, expected from the state program realization and will increase the timeperiod for analyzing the projects of The State Duma programs and The Chamber of Accounts. For the regular base the Federal plan of statistic works will actualize in the part of organizing well-timed monitoring of Russian Federation state programs realization movement.

It is necessary to improve the mechanism of risks administration of the failure to achieve the target indexes with the goal of minimize its negative influence to the state program realization results and rise the responsibility of the process participants of its development and realization. The qualitative and quantitative evaluation of risks, the fixing of its influence to the realization movement allows to improve the state programs effectiveness.

One of the problems of the state programs development is contradiction of the planning values of indexes series of the state programs with target values, which are consolidated in the decrees by the Russian Federation President dated May 7, 2012, which obstruct the efficiency evaluation of its realization. In this connection it is being viewed the purposeful inclusion of indexes, which reflect the decrees implementation into the state programs by responsible performers, and the correction of planning indexes according to the strategy of social-economic development.

For the report evaluation about the state programs realization is being studied the information about budget assignations using of the federal budget for the state programs realization. However, data about cash accomplishment of federal budget for the realization of state programs series being introduced by responsible performer don't accord to the data introduced by Russian Ministry of Finance. It is connected to the lack of spending reflection in federal budget in the section of the main events of state programs inside active budget classification, which considers budget efficiency just in the section of the main state programs, under- programs and federal target programs [4]. In the result it is being watched minor deviations of the data by responsible performers from the data by Russian Federation Ministry of Finance in 2\% in more or less way.

To avoid variance in data by responsible performer and The Ministry of Finance of the Russian Federation can be made the organizing way of interconnection of the state programs development process and preparation of federal budget project according to necessity of realization of the principle of single-entry information to informative system "electronic budget" and The Portal of State Programs of Russian Federation.

For the programs realization is being given rather big value of financial resources in conditions of its limitation. Because of costs waving for oil it is hard to forecast the budget of the future period, so invested budget resources should be used with maximum efficiency: in the program should be written strictly values and terms of making budget appropriation for all directions. It should be noticed that incompetence of some federal agencies to redistribute effectively financial resources in conditions of limitation of the program part of budget, which can be solved by making training workshops. In such a way, the problems of optimization and rising of budget spending efficiency of state programs in Russian Federation stay topical. The implementation of continuous monitoring of the taste programs realization, including monitoring of results indexes of inter- budget subsidies using, allow to rise budget efficiency. With the aim of weight declining to the budget system of Russian Federation it is necessary to make set of measures for calling in out-budget financial sources, including financial resources of legal entities.

During transition to the program budget should be followed deep procedural and hierarchical consistence of strategic planning process. State programs should have intersectional and inter-discipline approach, not narrowdepartmental as it happens nowadays. It is being included just investing to events connected to department, which develops the project of its program. In this case it is important to control financial resources distribution between events, made by agencies under another ministry. 


\section{AN IMPROVEMENT OF QUALITY FORMING OF STATE PROGRAMS TARGET INDEXES AND UNIVERSALIZATION OF AN ACCOUNTING Method of ITS ACHIEVEMENT DEGREE}

As a result of state programs audit made by The Chamber of Accounts of the Russian Federation, was detected an imbalance of goals, aims, indicators, events and financial resources of state programs and also its incomplete connection to the existing long-term documents of socialeconomic development and all the strategies, which were accepted in federal level. The goals of many state programs have indistinct statements, are not enough coordinated to state programs problems and sometimes an achievement of the stated goals isn't provided by the stated goals realization.

In the methods of accounting indexes should be used the same units and accounting period to provide a comparing of the taken results.

Besides it should be avoided the using of a big number of indexes, because it leads to the informative overload and reduces information usefulness, an attention should be detected to the main goals and problems of the state program. State program's developers should avoid the using of indexes, which don't have the strict connection to the problem, which is being planned to solve as a result of state program's realization [5].

As a result of a number of indexes excess, state programs suffer from event's and under-programs over-saturation; the work for program structuring becomes ineffective. Usually in these programs easily attainable indexes are indicated which are easy for reporting. In big number of indexes it is rather hard to detect its values, because the data by Federal Department of State Statistics and industrial statistics is not enough for all the indexes in full measure. Among the state program indexes should be only indexes, which information is available in official statistics and which characterize activity connected to each industry [6].

Besides it is necessary to find the balance between social and economic indexes, because the using of big number of financial indexes comparing to the quality indexes show the distortion of the whole picture. The problem of strategic goals balance of Russian Federation development and federal budget forming can be solved by introducing conceptual changes into the existing normative-legal base.

\section{The NoRMATIVE-LEGAL BASE DEVELOPMENT}

An important problem in development system, realization and state programs evaluation is lack of full-complex system of strategic documents, connected to state programs. For rising the efficiency of state programs it is expediently to harmonize normative-legal and methodological documents, which will contribute the quality rising of its development and strict maintenance of order of state programs realization.

Weakness of the normative base, which gives criterions to certain documents quality and supports the systematization of its connections, reduces strategic process efficiency. This problem can be solved by making deep qualitative analysis of normative-legal and methodological base of strategic planning and budget process by federal state educational budget institutions of high education or analytics centers an research institutes for the aim to detect keyproblems and composing recommendations for documents composition of strategic planning. The result of this step making will be the systematization of existing documents and harmonization of them by its composition and logic [7].

Following the document harmonization will be removed breaks in target connection, budget processes and a process of responsibility and authorization fixing, and the system break of goal-setting and evaluation, removed negative effects of parallel existing of new and old elements of planning and created conditions for full evaluation of socialeconomic efficiency of state programs.

\section{CONCLUSION}

In such a way state programs nowadays fixed in a quality of the key instruments of effective budget planning, however the full system of social-economic efficiency evaluation of state programs has not been formed so far, and the quality of development of some state programs face certain problems. Because there is a lack of a clear-cut connection between the budget appropriation and results and the method of socialeconomic efficiency evaluation is not developed enough, for the last time in state administration area were made active steps for state programs administration process improving [8]. The suggested directions for improving the development quality in existing work, realization and state programs efficiency evaluation will be the factor of balanced budget process and will contribute a reduction of social-economic problems in the Russian Federation.

\section{REFERENCES}

[1] The Federal law as of 28.06.2014 No. 172-FZ "On strategic planning in the Russian Federation" [Electronic resource]. URL: http://www.con-sultant.ru/docu-ment/cons_doc_LAW_164841.

[2] E.Yu. Evstafyeva, Improvement of methods of development and evaluation of state programs of the subjects of the Russian Federation: thesis. Ulan-Ude, 2014.

[3] The consolidated annual progress report on the implementation and evaluation of the effectiveness of state programs of the Russian Federation on the results 2014 of 28.05 .2015 No. 13931-NP/D19i.

[4] The budget code of the Russian Federation of 31.07.1998 № 145-FZ.

[5] Audit Chamber of the Russian Federation // Report of T. A. Golikova on the results of the au-dit of state programs [Electronic resource]. URL: http://audit.gov.ru/structure/golikova-tatyanaalekseevna/speeches/25119.

[6] I.L. Yurzinova, V.N. Nezamaikin, Improvement of the Mechanisms of Management of Socio-Economic Development // Advances in Economics, Business and Management Research, volume 32. 3rd International Conference on Economics, Management, Law and Education (EMLE 2017). Atlantis Press, 2017. pp. 77-80.

[7] A.V. Klimenko, V.A. Korolev, D.Yu. Dvinsky et al, On the harmonization of documents of state strategic planning. M.: ID of the Higher school of Economics, 2015.

[8] I.L. Yurzinova, I.P. Doroshina, D.E. Morkovkin, Development of the recommendations on improvement of the system of evaluation of social and economic effectiveness of state programs as a tool of strategic planning // Economy and Management: Problems, Solutions, 2018, No. 5, vol. 7 (77), pp. 64-69. 